\title{
Discrete Burr Type Iii Distribution
}

\author{
Afaaf A. AL-Huniti ${ }^{1, *}$, Gannat R. AL-Dayian ${ }^{2}$ \\ ${ }^{1}$ Department of Mathematics, King Abdulaziz University, Rabigh, Kingdom of Saudi Arabia \\ ${ }^{2}$ Department of Statistics, AL-Azhar University, Cairo, Egypt
}

\begin{abstract}
In this paper, the discrete Burr type III distribution is introduced using the general approach of discretizing a continuous distribution and proposed it as a suitable lifetime model. The equivalence of continuous and discrete Burr type III distribution is established. Some important distributional properties and estimation of the parameters, reliability, failure rate and the second rate of failure functions are discussed based on the maximum likelihood method and Bayesian approach.
\end{abstract}

Keywords Burr Type III Distribution, Discrete Lifetime Models, Reliability, Failure Rate, Maximum Likelihood Estimation, Bayes Estimation

\section{Intro duction}

An important aspect of lifetime analysis is to find a lifetime distribution that can adequately describe the ageing behavior of the device concerned. Most of the lifetimes are continuous in nature and hence many continuous life distributions have been proposed in literature. On the other hand, discrete failure data are arising in several common situations for example:

- Reports on field failure are collected weekly, monthly and the observations are the number of failures, without a specification of the failure times.

- A piece of equipment operates in cycles and experimenter observes the number of cycles successfully completed prior to failure. A frequently referred example is copier whose life length would be the total number of copies it produces. Another example is the number of on/off cycles of a switch before failure occurs, see Lai and Xie[1].

In the last two decades, standard discrete distributions like geometric and negative binomial have been employed to model life time data. Usually, if the discrete model is used with lifet ime data, it is a multino mial distribution. This arises because effectively the continuous data have been grouped, see Lawless[2]. However, there is a need to find more plausible discrete lifetime distributions to fit to various types of lifetime data. For this purpose, discretizing popular continuous lifetime distributions can be helpful in this manner, since, it effects on speed, accuracy and understandability of the generated data using these discrete lifetime models.

\subsection{Discretizing a Continuous Distribution}

* Corresponding author:

a.ali94@hotmail.com (Afaaf A. AL-Huniti)

Published online at http://journal.sapub.org/ajms

Copyright (C) 2012 Scientific \& Academic Publishing. All Rights Reserved
A continuous failure time model can be used to generate a discrete model by introducing a grouping on the time axis. If the underlying continuous failure time $\mathrm{X}$ has the reliability function (RF), $\mathrm{R}(\mathrm{x})=\mathrm{P}[\mathrm{X} \geq \mathrm{x}]$,

and times are grouped into unit intervals so that the discrete observed variable is $\mathrm{dX}=[\mathrm{X}]$, the largest integer part of $\mathrm{X}$, the probability mass function (pmf) of $\mathrm{dX}$ can be written as

$$
\begin{gathered}
\mathrm{p}(\mathrm{x})=\mathrm{P}[\mathrm{dX}=\mathrm{x}]=\mathrm{P}[\mathrm{x} \leq \mathrm{dX}<x+1] \\
=\mathrm{R}(\mathrm{x})-\mathrm{R}(\mathrm{x}+1) ; \mathrm{x}=0,1,2 \ldots
\end{gathered}
$$

The pmf of discrete random variable $(\mathrm{dX})$, can be viewed as discrete concentration of the pdf of $\mathrm{X}$. The first and easiest in this approach is the geometric distribution with $\mathrm{pmf}$

$$
\mathrm{p}(\mathrm{x})=\theta^{\mathrm{x}}(1-\theta)=\theta^{\mathrm{x}}-\theta^{\mathrm{x}+1} \quad ; \mathrm{x}=0,1,2, \ldots
$$

this is obtained by discretizing the exponential distribution with $\mathrm{RF}$

$$
\begin{aligned}
\mathrm{R}(\mathrm{x}) & =\mathrm{e}^{-\lambda \mathrm{x}} ; \quad \lambda, \mathrm{x}>0 . \text { Here } \theta=\mathrm{e}^{-\lambda},(0<\theta<1) . \\
& =\theta^{\mathrm{x}} .
\end{aligned}
$$

The interests in discrete failure data came relatively late in comparison to its continuous analogue. The subject matter has to some extent been neglected. It was only briefly mentioned by few scientists. Khan, Khalique and Abouammoh[3], discussed two discrete Weibull distributions (type I and type II), and suggested a simple method to estimate the unknown parameters for one of them, since the usual methods of estimation are not easy to apply. Kulasekera[4] presented approximate maximum likelihood estimators of the parameters of a discrete Weibull distribution under censoring.

A discrete analogue of the normal distribution was obtained[5], that is characterized by maximum entropy, specified mean and variance, and integer support on $(-\infty, \infty)$. Szablowski[6], introduced new natural parameters in a formula defining a family of discrete normal distributions, where one of the parameters is closely related to the expectation and the other to the variance of that family. The discrete version of the normal and Rayleigh distributions 
were also proposed by Roy[7],[8] respectively. The discrete Weibull models were obtained[9], in order to model the number of cycles to failure when components are subjected to cyclical loading. In addition, some distributional properties for these models were presented.

A discrete version of the Laplce (double exponential) distribution was derived by Inusah and Ko zubowski[10], and discussed some of its statistical properties and statistical issues of estimation under the discrete Laplace model. The discrete Burr type XII and Pareto distribution were obtained[11], using the general approach of discretizing and then, some important distributional properties and estimation of reliability characteristics were proposed.

A discrete inverse Weibull distribution was proposed[12], which is a discrete version of the continuous inverse Weibull variable, defined as $\mathrm{X}^{-1}$ where $\mathrm{X}$ denotes the continuous Weibull random variable. The discrete version of Lindley distribution was introduced[13], by discretizing the continuous failure model of the Lindley distribution. Also, a compound discrete Lindley distribution in closed form is obtained after revising some of its properties.

A discrete generalized exponential distribution of a second type $\left(\operatorname{DGE}_{2}(\alpha, \rho)\right)$, was presented[14], which can be considered as another generalization of the geometric distribution.

A discrete analog of the generalized exponential distribution $(\operatorname{DGE}(\alpha, \rho))$ was presented[15], which can be viewed as another generalization of the geometric distribution, and some of its distributional and moment properties were discussed. Burr type III distribution proposed as a lifetime model, see[16], the author discussed the distributional and the reliability properties of BurrIII(c, k).

In this paper, a discrete analogue of the BurrIII(c, k) distribution is introduced, since, it plays an important role in environment and other allied sciences. It is called discrete Burr type III distribution denoted by dBurrIII(c, $\theta$ ). This distribution is suggested as a suitable lifetime model to fit a range of discrete lifetime data. The rest of the paper is organized as follows: In Section 2, BurrIII(c, k) distribution is given with its reliability characteristics. The discrete analogue of BurrIII(c, k) distribution is developed with its distributional properties and reliability characteristics along with a graphical description. In Section 3, some important results on dBurrIII(c, $\theta)$ are proved. The maximum likelihood (ML) and Bayes estimations in $\operatorname{dBurrIII}(c, \theta)$ are illustrated in detail through a simulation studies in Section 4.

\section{The Model}

\subsection{Continuous Burr Type III Distribution}

A lifetime rv $\mathrm{X}$ follows the Burr type III distribution BurrIII(c, $k)$ if its pdf is given by $\mathrm{f}(\mathrm{x} \mid \mathrm{c}, \mathrm{k})=\left\{\begin{array}{cc}0 & \text { otherwise } \\ \mathrm{ckx}^{-\mathrm{c}-1}\left(1+\mathrm{x}^{-\mathrm{c}}\right)^{-\mathrm{k}-1}, & \mathrm{x}>0,(\mathrm{c}, \mathrm{k}>0)\end{array}\right.$ the corresponding survival function (RF), failure rate function (HRF) and the second rate of failure function (SHRF) are respectively given by

$$
\begin{aligned}
& \mathrm{R}(\mathrm{x})=1-\left[1+\mathrm{x}^{-\mathrm{c}}\right]^{-\mathrm{k}}, \mathrm{x}>0,(\mathrm{c}, \mathrm{k}>0) \\
& \mathrm{h}(\mathrm{x})=\frac{\mathrm{ckx}-\mathrm{c}^{-1}\left(1+\mathrm{x}^{-\mathrm{c}}\right)^{-k-1}}{1-\left[1+\mathrm{x}^{-\mathrm{c}}\right]^{-\mathrm{k}}}, \mathrm{x}>0,(\mathrm{c}, \mathrm{k}>0)
\end{aligned}
$$

and

$$
\begin{gathered}
\mathrm{h}^{*}(\mathrm{x})=\log \left[\frac{\mathrm{R}(\mathrm{x})}{\mathrm{R}(\mathrm{x}+1)}\right]=\log \left[\frac{1-\left(1+\mathrm{x}^{-\mathrm{c}}\right)^{-\mathrm{k}}}{1-\left\{1+(1+\mathrm{x})^{-\mathrm{c}}\right\}^{-k}}\right] \\
\mathrm{x}>0,(\mathrm{c}, \mathrm{k}>0) .
\end{gathered}
$$

\subsection{Discrete Burr III Distribution}

Based on the reliability function of continuous BurrIII rv $\mathrm{X}$, which is given by (3), the $\mathrm{R}(\mathrm{x})$ for $\operatorname{dBurrIII}(\mathrm{c}, \theta)$ distribution at integer points of $X$, is given by

$$
\begin{gathered}
\mathrm{R}(\mathrm{x})=1-\theta^{\log \left(1+\mathrm{x}^{-\mathrm{c}}\right)}, \\
\text { where } \theta=\mathrm{e}^{-\mathrm{k}} \text { and }(0<\theta<1) .
\end{gathered}
$$

Here, note that $\mathrm{R}(\mathrm{x})$ is same for BurrIII(c, $\mathrm{k})$ distribution and $\operatorname{dBurrIII}(c, \theta)$ distribution at the integer points of $\mathrm{x}$. Also, it is a positively skewed distribution.

Now, by using (1), the pmf of the discrete Burr type III distribution with the parameters $c$ and $\theta$, $\operatorname{dBurrIII}(c, \theta)$, can be define as

$$
\begin{aligned}
& \mathrm{p}(\mathrm{x})=\mathrm{R}(\mathrm{x})-\mathrm{R}(\mathrm{x}+1) \\
& =\theta^{\log \left[\frac{161}{4} 1+(1+x)^{-c}\right\}}-\theta^{\log \left(1+x^{-c}\right)}, x=0,1,2, \ldots
\end{aligned}
$$

\subsubsection{The Failure Rate $\mathbf{h}(\mathbf{x})$ is Given by}

The HRF or the failure rate function is given by

$$
\mathrm{h}(\mathrm{x})=\frac{\mathrm{p}(\mathrm{x})}{\mathrm{R}(\mathrm{x})}=\frac{\theta^{\log \left[\operatorname{lip}_{1}+(1+\mathrm{x})^{-\mathrm{c}}\right\}_{-} \log \left(1+\mathrm{x}^{-c}\right)}}{1-\theta^{\log \left(1+\mathrm{x}^{-c}\right)}}, \mathrm{x}=0,1,2, \ldots
$$

to study the behaviors of this function see Fig.(3).

\subsubsection{The Second Rate of Failure $\mathbf{h}^{*}(\mathbf{x})$ is Given by}

For discrete distributions, failure rate $\mathrm{h}(\mathrm{x})$ is a conditional probability with unity as its upper bound. It was pointed out that calling this the failure rate function might add to the confusion that is already common in industry that failure rate and failu re probability are sometimes mixed-up[9]. To solve this problem they introduced second rate of failure $\mathrm{h}^{*}(\mathrm{x})$ with the same monotonicity as $\mathrm{h}(\mathrm{x})$.

For dBurrIII(c, $\theta$ ) we have

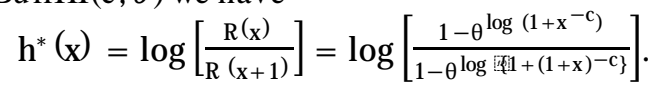

\section{Remark:}

Note that the expressions for $\mathrm{R}(\mathrm{x}), \mathrm{h}(\mathrm{x})$ and $\mathrm{h}^{*}(\mathrm{x})$ for dBurrIII(c, $\theta)$ can be directly obtained from those of BurrIII(c, k) distribution, by setting

$$
(\mathrm{k}=-\log \theta) \equiv\left(\theta=\mathrm{e}^{-\mathrm{k}}\right) .
$$

\subsubsection{The $\mathbf{r}^{\text {th }}$ Moment of dBurrIII(c, $\left.\boldsymbol{\theta}\right)$ is Given by}

In particular: 
(i) The mean of lifetime $\mu$ of $\operatorname{dBurrIII}(c, \theta)$ can be obtained by using (10) as follows

$$
\grave{\mu}_{1}=\mu=\sum_{\mathrm{x}=0}^{\infty} \mathrm{x}\left[\theta^{\log \left[\operatorname{cip}_{1}+(1+\mathrm{x})^{-\mathrm{c}}\right\}}-\theta^{\log \left(1+\mathrm{x}^{-\mathrm{c}}\right)}\right] .
$$

(ii) The second moment is given by

$$
\left.\grave{\mu}_{2}=\sum_{x=0}^{\infty} x^{2}\left[\theta^{\log \left[\text { iqi } 1+(1+x)^{-c}\right.}\right\}-\theta^{\log \left(1+x^{-c}\right)}\right] .
$$

(iii) The variance $\mathrm{V}(\mathrm{c}, \theta)$ of $\operatorname{dBurrIII}(\mathrm{c}, \theta)$ can be obtained by using (11) and (12) as follows

$$
\begin{aligned}
& \mathrm{V}(\mathrm{c}, \theta)=\grave{\mu}_{2}-\mu^{2}=\sum_{\mathrm{x}=0}^{\infty} \mathrm{x}^{2}\left[\theta^{\log \left[\mathrm{Cl}^{1}+(1+\mathrm{x})^{-\mathrm{c}}\right\}}-\theta^{\log \left(1+\mathrm{x}^{-\mathrm{c})}\right.}\right] \\
& -\left[\sum_{x=0}^{\infty} x\left[\theta^{\log \left[\operatorname{lig}_{1} 1+(1+\mathrm{x})^{-\mathrm{c}}\right\}}-\theta^{\log \left(1+\mathrm{x}^{-\mathrm{c}}\right)}\right]\right]^{2}
\end{aligned}
$$

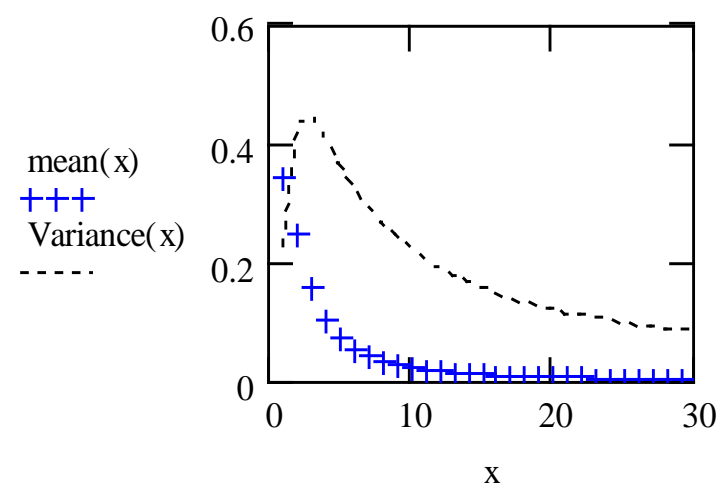

Figure 1. Plot for the mean and the variance of $\mathrm{dBurrIII}(\mathrm{c}, \boldsymbol{\theta})$

Obviously, from Fig.(1), the mean of dBurrIII(c, $\theta)$ is decreasing. Also, the variance of $\operatorname{dBurrIII}(c, \theta)$ is decreasing and it's noticeable from the graph that the mean is decreasing faster than the variance. Although the variance for dBurrIII(c, $\theta$ ) tends to increase at the beginning but after that it adopts the same behavior as the mean.

(iv) The $3^{\text {rd }}$ mo ment is given by

$$
\grave{\mu}_{3}=\sum_{\mathrm{x}=0}^{\infty} \mathrm{x}^{3}\left[\theta^{\log \left[\cos _{1} 1+(1+\mathrm{x})^{-\mathrm{c}}\right\}}-\theta^{\log \left(1+\mathrm{x}^{-\mathrm{c}}\right)}\right]
$$

(v) The $4^{\text {th }}$ mo ment is given by

$$
\grave{\mu}_{4}=\sum_{\mathrm{x}=0}^{\infty} \mathrm{x}^{4}\left[\theta^{\log \left[\operatorname{cin}_{1} 1+(1+\mathrm{x})^{-\mathrm{c}}\right.}-\theta^{\log \left(1+\mathrm{x}^{-\mathrm{c}}\right)}\right]
$$

(vi) The skewness $\alpha_{3}$ of dBurrIII(c, $\left.\theta\right)$ can be obtained by using (11), (12), (13) and (14) as follows

$$
\begin{gathered}
\alpha_{3}=\frac{\grave{\mu}_{3}-2 \grave{\mu}_{2} \mu+\mu^{3}}{\mathrm{~V}^{3 / 2}} \\
=\frac{\sum_{\mathrm{x}=0}^{\infty} \mathrm{x}^{3}\left[\theta^{\left.\log \left\{1+(1+\mathrm{x})^{-c}\right\}-\theta^{\log \left(1+\mathrm{x}^{-c}\right)}\right]}\right.}{[\mathrm{V}]^{\frac{3}{2}}} \\
-\frac{2 \mu \sum_{\mathrm{x}=0}^{\infty} \mathrm{x}^{2}\left[\theta^{\left.\log \left\{1+(1+\mathrm{x})^{-c}\right\}-\theta^{\log \left(1+\mathrm{x}^{-c}\right)}\right]+\mu^{3}}\right.}{[\mathrm{V}]^{\frac{3}{2}}}
\end{gathered}
$$

(vii) The kurtosis $\alpha_{4}$ of dBurrIII(c, $\theta$ ) can be obtained by using (11), (12), (13), (14) and (15) as follows

$$
\begin{aligned}
& \alpha_{4}=\frac{\grave{\mu}_{4}-4 \grave{\mu}_{3} \mu+6 \grave{\mu}_{2} \mu^{2}-3 \mu^{4}}{\mathrm{~V}^{2}} \\
= & \frac{\sum_{\mathrm{x}=0}^{\infty} \mathrm{x}^{4}\left[\theta^{\log \left\{1+(1+\mathrm{x})^{-\mathrm{c}}\right\}-\theta^{\log (1+\mathrm{x}-\mathrm{c})}}\right]}{[\mathrm{V}]^{2}}
\end{aligned}
$$

$$
\begin{aligned}
&- \frac{4 \mu \sum_{\mathrm{x}=0}^{\infty} \mathrm{x}^{3}\left[\theta^{\left.\log \left\{1+(1+\mathrm{x})^{-\mathrm{c}}\right\}-\theta^{\log \left(1+\mathrm{x}^{-\mathrm{c}}\right)}\right]}\right.}{[\mathrm{V}]^{2}} \\
&+\frac{6 \mu^{2} \sum_{\mathrm{x}=0}^{\infty} \mathrm{x}^{2}\left[\theta^{\left.\log \left\{1+(1+\mathrm{x})^{-c}\right\}-\theta^{\log \left(1+\mathrm{x}^{-c}\right)}\right]-3 \mu^{4}}\right.}{[\mathrm{V}]^{2}}
\end{aligned}
$$

\subsubsection{The Probability Generating Function $\mathbf{G}(\mathbf{t})$ for} dBurrIII(c, $\boldsymbol{\theta})$ is Given by

$$
\begin{gathered}
G(t)=E\left(t^{x}\right)=\sum_{x=0}^{\infty} t^{x} p(x) \\
=\sum_{x=0}^{\infty} t^{x}\left[\theta^{\log \left[1+(1+x)^{-c}\right.}-\theta^{\log \left(1+x^{-c}\right)}\right]
\end{gathered}
$$

It is difficult to get closed form analytical expression for the probability generating function, one need to evaluate this numerically, given specific para meters values.

In particular, the mean of lifetime $\mu$ of $\operatorname{dBurrIII}(c, \theta)$ can be obtained by using the first derivative of (18), which is known as the first factorial moment and it is given by

(i) $\grave{G}(1)=\sum_{x=0}^{\infty} x\left[\theta^{\log \left[\operatorname{cip}^{1} 1+(1+\mathrm{x})^{-\mathrm{c}}\right\}}-\theta^{\log \left(1+\mathrm{x}^{-\mathrm{c}}\right)}\right]=\mu$. (19)

It is clear that the second factorial mo ment can be obtained by getting the second derivative of (18) as follows

$$
\begin{aligned}
& \text { (ii) } \mu_{[2]}=\grave{\mathrm{G}}(1)=\sum_{\mathrm{x}=0}^{\infty}[\mathrm{x}(\mathrm{x}-1)]\left[\theta^{\log \left[T_{1}+(1+\mathrm{x})^{-\mathrm{c}}\right\}}-\right. \\
& \theta \log 1+\mathrm{x}-\mathrm{c} \text {. }
\end{aligned}
$$

More generally, the $\mathrm{r}^{\text {th }}$ factorial mo ment is given by

$$
\begin{gathered}
\text { (iii) } \mu_{[\mathrm{r}]}=\mathrm{G}^{\mathrm{r}}(1) \\
=\sum_{\mathrm{x}=0}^{\infty}[\mathrm{x}(\mathrm{x}-1)(\mathrm{x}-2) \ldots(\mathrm{x}-\mathrm{r}+1)]\left[\theta^{\log \left[\operatorname{li}_{1}+(1+\mathrm{x})^{-\mathrm{c}}\right\}}\right. \\
\left.-\theta^{\log \left(1+\mathrm{x}^{-\mathrm{c}}\right)}\right] ; \mathrm{r}=1,2, \ldots
\end{gathered}
$$

From (19) and (20) the variance V(c, $\theta)$ of $\operatorname{dBurrIII}(c, \theta)$ is given by

$$
\begin{aligned}
& \text { (iv) } \mathrm{V}(\mathrm{c}, \theta)=\grave{\mathrm{G}}(1)+\mu-\mu^{2} \\
& \left.=\sum_{x=0}^{\infty} x^{2} \theta^{\log \left\{1+(1+x)^{-c}\right.}\right\}\left[1-\theta^{\log \left\{1+(1+x)^{-c}\right\}}\right] \\
& -x^{2} \theta^{\log \left(1+x^{-c}\right)}\left[1+\theta^{\log \left(1+x^{-c}\right)}\right] \\
& +2 x^{2}\left[\theta^{\log \left\{1+(1+x)^{-c}\right\}+\log \left(1+x^{-c}\right)}\right]
\end{aligned}
$$

2.2.5. The Characteristic Function $\boldsymbol{\varphi}_{\mathbf{x}}(\boldsymbol{\omega})$ for dBurrIII(c, $\left.\boldsymbol{\theta}\right)$ is Given by

$$
\begin{aligned}
\varphi_{\mathrm{x}}(\omega)=\mathrm{E}\left(\mathrm{e}^{\mathrm{ix} \omega}\right)=\sum_{\mathrm{x}=0}^{\infty} \mathrm{e}^{\mathrm{ix} \omega}\left[\theta^{\log \left[\operatorname{lig}_{1}+(1+\mathrm{x})^{-\mathrm{c}}\right\}}-\right. \\
\left.\theta^{\log \left(1+\mathrm{x}^{-\mathrm{c}}\right)}\right]
\end{aligned}
$$

and since,

$$
\grave{\mu}_{\mathrm{r}}=\frac{1}{(\mathrm{i})^{\mathrm{r}}}\left[\frac{\mathrm{d}^{\mathrm{r}} \varphi_{\chi}(\omega)}{\mathrm{d} \omega^{\mathrm{r}}}\right]_{\omega=0} ; \quad \mathrm{r}=1,2, \ldots
$$

then,

$$
\grave{\mu}_{\mathrm{r}}=\sum_{\mathrm{x}=0}^{\infty} \mathrm{x}^{\mathrm{r}}\left[\theta^{\log \left[\operatorname{li}_{1}+(1+\mathrm{x})^{-\mathrm{c}}\right\}}-\theta^{\log \left(1+\mathrm{x}^{-\mathrm{c}}\right)}\right]
$$

which is clearly the same result in (10).

\subsection{Graphical Description}

The curves of two populations of $\operatorname{dBurrIII}(c, \theta)$ are plotted in Fig.(2), the first curve $\mathrm{p} 1(\mathrm{x})$ when $(\theta=.75$ and $\mathrm{c}=$ 1) and the the second one, $\mathrm{p} 2(\mathrm{x})$ when $(\theta=.25$ and $\mathrm{c}=$ 
$.5)$. The curves of the corresponding failure rate function and the second rate of failure function of $\operatorname{dBurrIII}(c, \theta)$ are illustrated in Fig.(3) and Fig.(4), respectively. Fig.(3) demonstrate some of the possible shapes of $h(x)$ for selected values of $\theta$ where $(c=.1)$, the first curve $h 1(x)$ at $(\theta=.2)$ and the second one, $\mathrm{h} 2(\mathrm{x})$ at $(\theta=2)$. It is obvious that $\mathrm{h}(\mathrm{x})$ is a decreasing function. In Fig.(4) some of the possible shapes of $\mathrm{h}^{*}(\mathrm{x})$ represented for selected values of $\theta$ and $\mathrm{c}$ where $(\theta=.1$ and $c=.5)$ in the first curve $S 1(x)$ and $(\theta=.99$ and $\mathrm{c}=1.5)$ in the second one, S2(x).

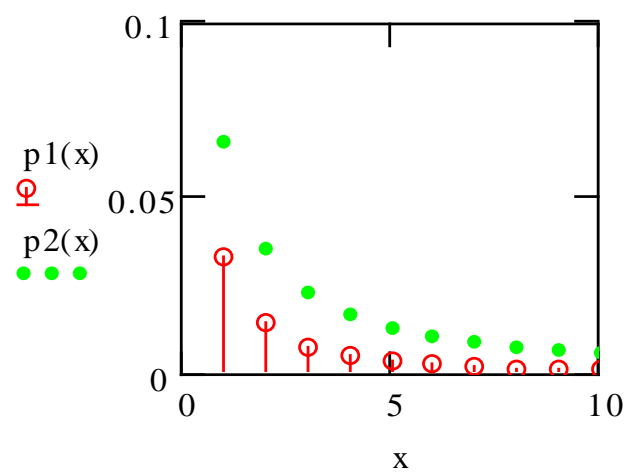

Figure 2. Plot of the probability mass function of $\mathrm{dBurrIII(c, \boldsymbol { \theta } )}$

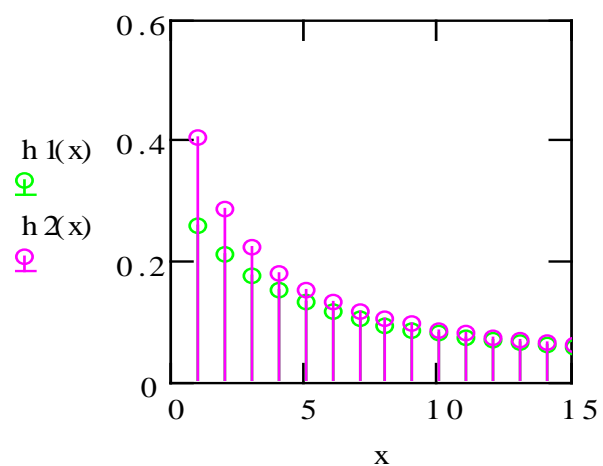

Figure 3. Plot of the failure rate function for $\operatorname{dBurrIII}(c, \theta)$

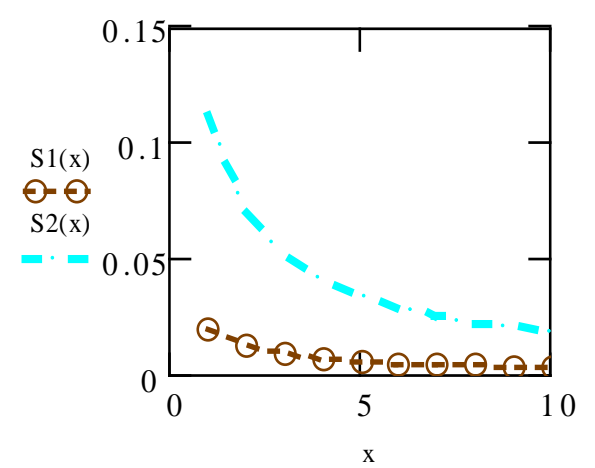

Figure 4. Plot of the second rate of failure for $\mathrm{dBurrIII}(\mathrm{c}, \theta)$

\section{Some Results on dBurrIII(c, $\theta)$}

\subsection{Result (1)}

If $\mathrm{X} \sim \operatorname{BurrIIII}(\mathrm{c}, \mathrm{k})$, then $\mathrm{Y}=[\mathrm{X}] \sim \mathrm{dBurrIII}(\mathrm{c}, \theta)$ with $\theta=\mathrm{e}^{-\mathrm{k}}$.
Proof

$$
\begin{aligned}
\mathrm{P}[\mathrm{Y} \geq \mathrm{y}] & =\mathrm{P}[[\mathrm{X}] \geq \mathrm{y}]=\mathrm{P}[\mathrm{X} \geq \mathrm{y}]=1-\left(1+\mathrm{y}^{-\mathrm{c}}\right)^{-\mathrm{k}} \\
& =1-\theta^{\log \left(1+\mathrm{y}^{-\mathrm{c}}\right)} ; \mathrm{y}=0,1,2, .
\end{aligned}
$$

Thus, $\mathrm{Y}=[\mathrm{X}] \sim$ dBurrIII $(\mathrm{c}, \theta)$.

\subsection{Result (2)}

Let $X_{i}^{\prime} s(i=1,2, \ldots n)$ be non-negative independently and identically distributed

$$
\text { (iid) integer valued rv's and } Y=\min _{1 \leq i \leq n} X_{i} \text {. }
$$

Then, $Y$ is dBurrIII $\left(c, \theta^{n}\right)$ if and only if $X_{i}$ is dBurrIII (c, $\theta)$.

Proof

Let $X_{i}(i=1,2, \ldots n)$ be iid dBurrIII(c, $\left.\theta\right)$, then,

$$
\mathrm{R}(\mathrm{x})=1-\theta^{\log \left(1+\mathrm{x}^{-\mathrm{c}}\right)} ; \quad \mathrm{x}=0,1,2, \ldots
$$

consider, $\forall \mathrm{y}=0,1,2, \ldots$

$$
\mathrm{R}(\mathrm{y})=\mathrm{P}[\mathrm{Y} \geq \mathrm{y}]=\left[\mathrm{P}\left[\mathrm{X}_{1} \geq \mathrm{y}\right]\right]^{\mathrm{n}}=1-\left(\theta^{\mathrm{n}}\right)^{\log \left(1+\mathrm{y}^{-\mathrm{c}}\right)},
$$

thus, $\mathrm{Y} \sim \mathrm{dBurrIII}\left(\mathrm{c}, \theta^{\mathrm{n}}\right)$.

\section{Conversely,}

$$
\text { let } \mathrm{R}(\mathrm{y})=1-\left(\theta^{\mathrm{n}}\right)^{\log \left(1+\mathrm{y}^{-\mathrm{c}}\right)} ; \mathrm{y}=0,1,2, \ldots \text {, then, }
$$

$$
\mathrm{R}(\mathrm{x})=\left[\mathrm{P}\left[\mathrm{X}_{1} \geq \mathrm{x}\right]\right]=\left[\mathrm{P}\left[\mathrm{X}_{1} \geq \mathrm{x}\right]\right]^{\frac{1}{\mathrm{n}}}=1-(\theta)^{\log \left(1+\mathrm{x}^{-\mathrm{c}}\right)} ; \mathrm{x}
$$

$$
=0,1,2, \ldots
$$

\subsection{Result (3)}

If $\mathrm{X}$ non-negative $\mathrm{rv}$ and $(\mathrm{t})$ is a positive number. Then, $\quad X_{t}=\left[X^{t}\right] \sim \operatorname{dBurrIII}\left(\frac{c}{t}, \theta\right)$ if and only if $\mathrm{X} \sim \operatorname{BurrIII}(\mathrm{c}, \mathrm{k})$.

Proof

Let $\mathrm{X} \sim \operatorname{BurrIII}(\mathrm{c}, \mathrm{k})$. Then, $\forall \mathrm{x}=0,1,2, \ldots$

$$
\begin{gathered}
P\left[X_{t} \geq x\right]=P\left[\left[X^{t}\right] \geq x\right]=P\left[X^{t} \geq x\right] \\
P\left[X \geq x^{\frac{1}{t}}\right]=1-\left(1+x^{-c / t}\right)^{-k} \\
=1-\theta^{\log \left(1+x^{-c / t}\right)} ; \quad x=0,1,2, \ldots,
\end{gathered}
$$

thus, $X_{t} \sim \operatorname{dBurrIII}\left(\frac{c}{t}, \theta\right)$.

Conversely,

let $X_{t} \sim \operatorname{dBurrIII}\left(\frac{c}{t}, \theta\right)$, then, $\forall y=0,1,2, \ldots$

$$
\begin{aligned}
& R_{t}(y)=P\left[X_{t} \geq y\right]=\left[P\left[X^{t}\right] \geq y\right] \\
& =P\left[X^{t} \geq y\right]=P\left[X \geq y^{\frac{1}{t}}\right]=R_{X}\left(y^{\frac{1}{t}}\right),
\end{aligned}
$$

Where,

$$
\begin{aligned}
R_{X}\left(y^{\frac{1}{t}}\right)=P\left[X_{t} \geq y\right] & =1-\theta^{\log \left(1+y^{-\frac{c}{t}}\right)} \\
= & 1-\left(1+y^{-\frac{c}{t}}\right)^{-k},
\end{aligned}
$$

substituting $\mathrm{y}^{\frac{1}{\mathrm{t}}}=\mathrm{x}\{\mathrm{x}$ will cover the whole interval $(0, \infty)$ for varying $t\}$, we get

$$
\begin{aligned}
& R_{X}(x)=P[X \geq x] \\
= & 1-\left(1+x^{-c}\right)^{-k} ; \quad x>0,
\end{aligned}
$$

which is the RF of $\operatorname{BurrIII}(\mathrm{c}, \mathrm{k})$. 


\subsection{Result (4)}

If $\mathrm{X} \sim \operatorname{BurrIII}(\mathrm{c}, \mathrm{k})$, then $\mathrm{Y}=\left[\log \left(1+\mathrm{X}^{-\mathrm{c}}\right)\right] \sim \operatorname{Geo}(\theta)$, the geometric distribution with $\theta=\mathrm{e}^{-\mathrm{k}}$.

\section{Proof}

Consider,

$\mathrm{P}[\mathrm{Y} \geq \mathrm{y}]=\mathrm{P}\left[\left[\log \left(1+\mathrm{X}^{-\mathrm{c}}\right)\right] \geq \mathrm{y}\right]=\mathrm{P}\left[\log \left(1+\mathrm{X}^{-\mathrm{c}}\right) \geq \mathrm{y}\right]$

$$
\begin{aligned}
&=P {\left[X \geq\left(e^{y}-1\right)^{-\frac{1}{c}}\right]=P\left[X \geq \frac{1}{\left(e^{y}-1\right)^{\frac{1}{c}}}\right] } \\
&=P\left[X \geq\left(e^{y}-1\right)^{-\frac{1}{c}}\right] \\
&=1-\left[1-\theta^{\log \left(1+\left(e^{y}-1\right)\right)}\right] \\
&=1-\left[1-\theta^{y}\right]=\theta^{y} ; y=0,1,2, \ldots,
\end{aligned}
$$

this is RF of geometric rv. Thus, $\mathrm{Y}_{\sim} \operatorname{Geo}(\theta)$.

\subsection{Result (5)}

If $\mathrm{X} \sim \operatorname{BurrIII}(\mathrm{c}, \mathrm{k})$, then $\mathrm{Y}=\left[\log \left(1+\mathrm{X}^{-\mathrm{c}}\right)^{-1}\right] \sim \operatorname{Geo}\left(\frac{1}{\theta}\right)$, where $\theta=\mathrm{e}^{-\mathrm{k}}$.

\section{Proof}

Consider,

$$
\begin{gathered}
P[Y \geq y]=P\left[\left[\log \left(1+X^{-c}\right)^{-1}\right] \geq y\right] \\
=P\left[-\log \left(1+X^{-c}\right) \geq y\right] \\
=P\left[-y \geq \log \left(1+X^{-c}\right)\right]=P\left[e^{-y} \geq 1+X^{-c}\right] \\
=P\left[X \leq\left(e^{-y}-1\right)^{-\frac{1}{c}}\right] \\
=1-\left[1-\theta^{\log \left(1+\left(e^{-y}-1\right)\right)}\right]=1-\left[1-\theta^{-y}\right]= \\
\theta^{-y} ; y=0,1,2, . .,
\end{gathered}
$$

That is RF of geometric rv. Thus, Y Geo $\left(\frac{1}{\theta}\right)$. The following figure summarizes some of the results on $\operatorname{dBurrIII}(c, \theta)$.

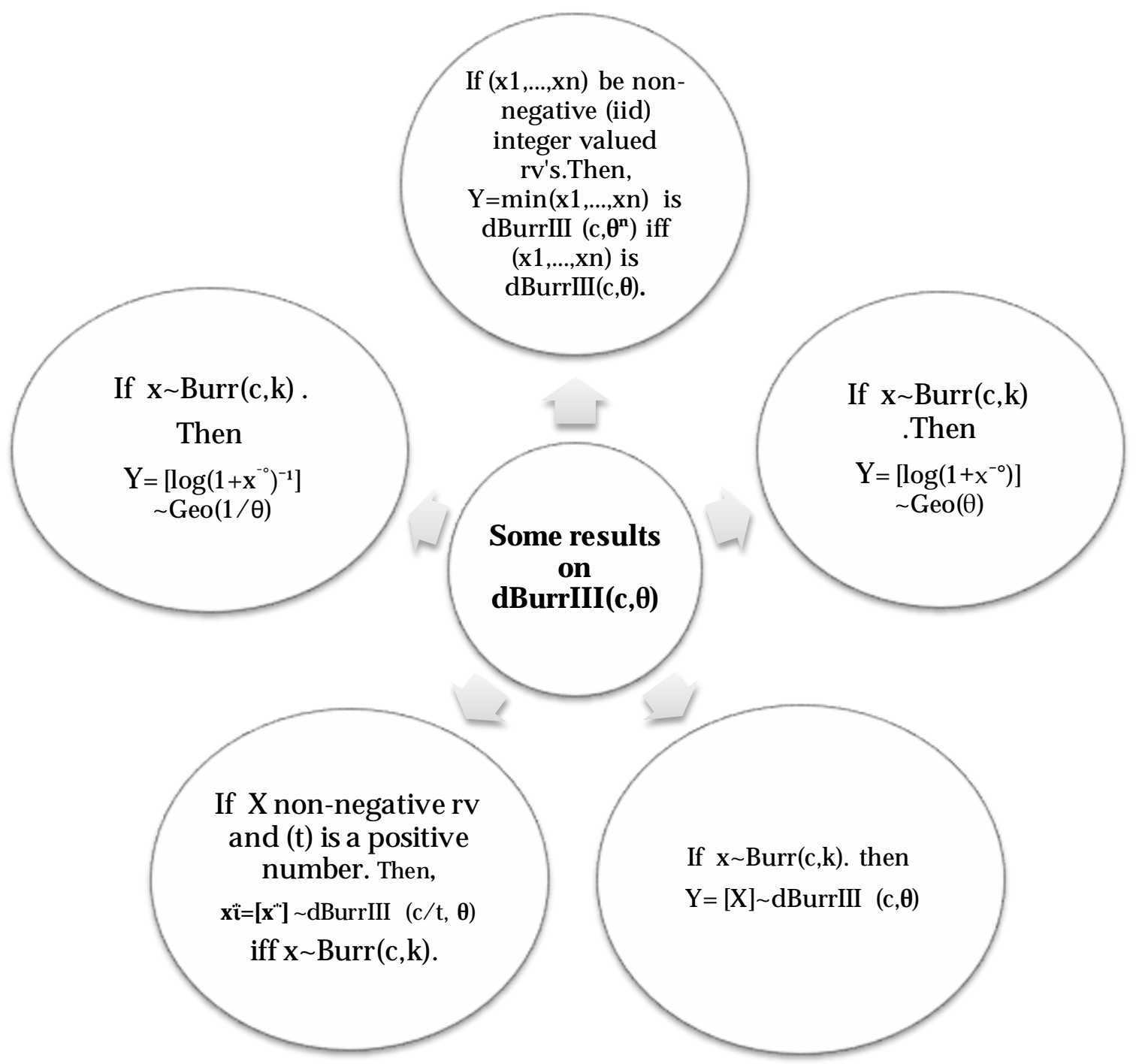

Figure 5. Summary of some results on $\operatorname{dBurrIII}(c, \boldsymbol{\theta})$ 


\section{Estimation of the Parameters of dBurrIII $(c, \theta)$}

\subsection{Estimation of the Parameters Based on the ML Method}

Let $\mathrm{n}$ items be put on test and their lifetimes are recorded as $X_{1}, X_{2}, \ldots, X_{n}$. If these $X_{i}$ 's are assumed to be iid rv's following $\mathrm{dBurrIII}(\mathrm{c}, \theta)$, their likelihood function is given by

$$
\begin{gathered}
\mathrm{L}(\mathrm{c}, \theta ; \underline{\mathrm{x}})=\prod_{i=1}^{n} p\left(x_{i}\right) \\
=\prod_{i=1}^{n}\left[\theta^{\log \left[\operatorname{cis}_{\left.1+\left(1+x_{i}\right)^{-c}\right\}}\right.}-\theta^{\log \left(1+x_{i}{ }^{-c}\right)}\right],
\end{gathered}
$$

and (23) can be rewritten as follows

$$
\begin{aligned}
& \mathrm{L}(\mathrm{c}, \theta ; \underline{x})=\prod_{\mathrm{i}=1}^{\mathrm{n}} \theta^{\log \left(1+\mathrm{x}_{\mathrm{i}}{ }^{-\mathrm{c})}\right.}\left[\theta^{\varnothing\left(\mathrm{x}_{\mathrm{i}}, \mathrm{c}\right)}-1\right], \\
& \text { where } \varnothing\left(\mathbf{x}_{\mathbf{i}}, \mathrm{c}\right)=\log \left[\frac{\left[1+\left(1+\mathbf{x}_{\mathbf{i}}\right)^{-\mathrm{c}}\right\}}{\left(1+\mathbf{x}_{\mathbf{i}}^{-c}\right)}\right] .
\end{aligned}
$$

Now, to find the two log-likelihood equations we need first to obtain the log-likelihood function which is given by $\log \mathrm{L}=\sum_{\mathrm{i}=1}^{\mathrm{n}}\left[\log \left(1+\mathrm{x}_{\mathrm{i}}{ }^{-\mathrm{c}}\right) \log \theta+\log \left\{\theta^{\varnothing\left(\mathrm{x}_{\mathrm{i}}, \mathrm{c}\right)}-1\right\}\right]$.

\subsubsection{Case I ( $\mathbf{c}$ is Known and $\boldsymbol{\theta}$ is Unknown)}

In this case, the MLE of the unknown parameter $\theta$ is $\hat{\theta}$, that is the solution of the following likelihood equation, with an observed sample this equation can be solved using an iterative numerical method.

$$
\frac{\partial \log \mathrm{L}}{\partial \theta}=\sum_{\mathrm{i}=1}^{\mathrm{n}}\left[\frac{\log \left(1+\mathrm{x}_{\mathrm{i}}^{-\mathrm{c}}\right)}{\widehat{\theta}}+\frac{\phi\left(\mathrm{x}_{\mathrm{i}}, \mathrm{c}\right) \widehat{\theta}^{\varnothing\left(\mathrm{x}_{\mathrm{i}}, \mathrm{c}\right)-1}}{\widehat{\theta}^{\varnothing\left(\mathrm{x}_{\mathrm{i}}, \mathrm{c}\right)}-1}\right]=0
$$

The solution of this equation will provide the MLE of $\theta$ by using numerical co mputation.

The MLE's of the reliability, the failure rate and the second rate of failure functions are obtained based on the invariance property of the ML, respectively as follows

and

$$
\begin{aligned}
& R(x)=1-\hat{\theta}^{\log \left(1+x^{-c}\right),}
\end{aligned}
$$

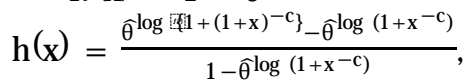

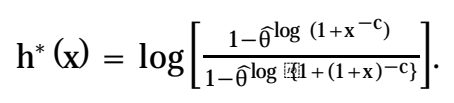

\subsubsection{Case II ( $\mathbf{c}$ and $\boldsymbol{\theta}$ are Un known)}

In this case, the solution of the following likelihood equations provide the MLE`s of the unknown parameters $\theta$ and $\mathrm{c}$, which are denoted by $\hat{\theta}$ and $\hat{\mathrm{c}}$, respectively. With an observed sample these equations can be solved using an iterative numerical method.

So those, the first derivatives with respect to $\theta$ and c, of the log-likelihood equation (25), are given by

$$
\begin{aligned}
& \frac{\partial \log \mathrm{L}}{\partial \theta}=\sum_{\mathrm{i}=1}^{\mathrm{n}}\left[\frac{\log \left(1+\mathrm{x}_{\mathrm{i}}^{-\mathrm{c}}\right)}{\widehat{\theta}}+\frac{\emptyset\left(\mathrm{x}_{\mathrm{i}}, \mathrm{c}\right) \widehat{\theta}^{\phi}\left(\mathrm{x}_{\mathrm{i}}, \mathrm{c}\right)-1}{\widehat{\theta}^{\phi\left(\mathrm{x}_{\mathrm{i}}, \mathrm{c}\right)}-1}\right]=0 \\
& \frac{\partial \log \mathrm{L}}{\partial \mathrm{c}}=\sum_{\mathrm{i}=1}^{\mathrm{n}}\left[\frac{\left(-\mathrm{x}_{\mathrm{i}}{ }^{-\hat{c}}\right) \log \theta \cdot \log \mathrm{x}_{\mathrm{i}}}{1+\mathrm{x}_{\mathrm{i}}-\hat{\mathrm{c}}}+\frac{\log \theta \phi^{\prime}\left(\mathrm{x}_{\mathrm{i}}, \hat{\mathrm{c}} \theta^{\phi\left(\mathrm{x}_{\mathrm{i}}, \hat{\mathrm{c}}\right)}\right.}{\theta^{\phi\left(\mathrm{x}_{\mathrm{i}}, \hat{\mathrm{c}}\right)}-1}\right]=0 \\
& \text { where }
\end{aligned}
$$

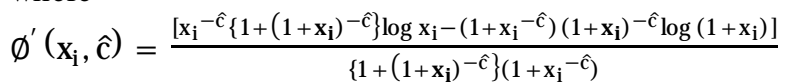

By using numerical computation, the solution of these normal equations will provide the MLE of $\theta$ and $\mathrm{c}$.

The MLE's of the reliability, the failure rate and the second rate of failure functions are obtained based on the invariance property of the $\mathrm{ML}$, respectively as follows

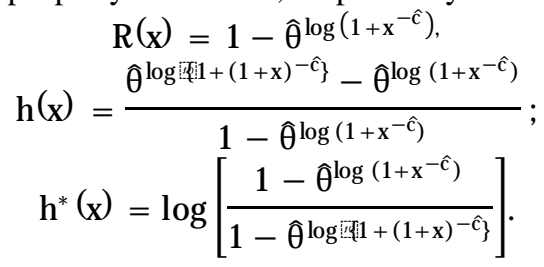

\subsection{Estimation of the Parameters based on Bayesian Approach}

\subsubsection{Case I ( $\mathbf{c}$ is Known and $\boldsymbol{\theta}$ is Unknown)}

Assume that the prior knowledge of $\theta$ is adequately represented by beta distribution with parameters (a) and (1) then the pdf of the prior density of $\theta$ is given by

$$
\begin{aligned}
\pi(\theta)=a \theta^{a-1} & ; 0<\theta<1 \\
\pi(\theta) & \propto \theta^{\mathrm{a}-1} .
\end{aligned}
$$

Combine the likelihood function (23) and the prior density (26) to obtain the posterior density of $\theta$ as follows

$$
\pi(\theta \mid \underline{\mathrm{x}}) \propto \theta^{\mathrm{a}+\sum \mathrm{w}_{1}-1}-\theta^{\mathrm{a}+\sum \mathrm{w}_{2}-1}
$$

Then

$$
\pi(\theta \mid \underline{\mathrm{x}})=Q(c) \theta^{\mathrm{a}+\sum \mathrm{w}_{1}-1}\left[1-\theta^{\omega}\right]
$$

where, $\left.\mathrm{w}_{1}=\log 11+\left(\mathrm{x}_{\mathrm{i}}+1\right)^{-\mathrm{c}}\right\}, \mathrm{w}_{2}=\log (1+$ $x i-$ cand $\omega=\left(w_{2}-w_{1}\right)$.

Now, obtaining the marginal distribution for $\underline{x}$, by integrating (27) over $\theta$ leads to:

$$
\begin{array}{r}
Q^{-1}(c)=\int_{0}^{1} \theta^{\mathrm{a}+\sum \mathrm{w}_{1}-1} \mathrm{~d} \theta-\int_{0}^{1} \theta^{\mathrm{a}+\sum \mathrm{w}_{2}-1} \mathrm{~d} \theta \\
=\frac{1}{\left(\mathrm{a}+\sum \mathrm{w}_{1}\right)}-\frac{1}{\left[\mathrm{a}+\sum \mathrm{w}_{2}\right]} \\
=\frac{\omega}{\left(\mathrm{a}+\sum \mathrm{w}_{1}\right) \cdot\left[\mathrm{a}+\sum \mathrm{w}_{2}\right]} \\
=\frac{\omega}{(\delta)(\tau)} ; \text { where } \delta=\left(\mathrm{a}+\sum \mathrm{w}_{1}\right) \text { and } \tau=\mathrm{a}+\sum \mathrm{w}_{2} . \\
\text { So, from (28) and }(29), \quad \theta \mid \underline{x} \text { distributed as followes: } \\
\pi(\theta \mid \underline{x})=\frac{(\delta)(\tau)}{\omega} \cdot \theta^{\delta-1}\left[1-\theta^{\omega}\right] ; \quad 0<\theta<1
\end{array}
$$

Assuming a squared-error loss function and informative prior, the Bayes estimate of the parameter $\theta$ is given by

$$
\theta^{*}=\mathrm{E}(\theta \mid \underline{\mathrm{x}})=\frac{(\delta)(\tau)}{(\delta+1)[\delta+\omega+1]} .
$$

Based on binary loss function, which is the mode of $\pi(\theta \mid \underline{x})$, the highest post estimate (HPE) of the parameter $\theta$ is given by

$$
\theta^{*}=\left[\frac{\delta-1}{\delta+\omega-1}\right]^{\frac{1}{\omega}} .
$$

Assuming a modified LINEX loss function, the Bayes estimate of the parameter $\theta$ is given by

$$
\theta^{*}=\frac{\mathrm{E}\left(\frac{1}{\theta}\right)}{\mathrm{E}\left(\frac{1}{\theta^{2}}\right)}=\frac{(\delta-2)[\delta+\omega-2]}{(\delta-1)[\delta+\omega-1]} .
$$

Also, under General entropy loss function, the Bayes estimate of the parameter $\theta$ is given by

$$
\theta^{*}=\left[\mathrm{E}\left(\theta^{-\mathrm{q}}\right)\right]^{-\frac{1}{q}}=\left[\frac{(\delta)(\tau)}{(\delta+\omega-q)(\delta-q)}\right]^{-\frac{1}{q}} .
$$

Now, from (30) considering a function of $\theta$ where $\left(\theta^{\omega}=\mathrm{z}\right)$ in order to get a well known form for the posterior density of the new parameter $\theta^{\omega}$, then $\pi(\mathbf{z} \mid \underline{x})$ will be at the 
following form

$$
\pi(\mathrm{z} \mid \underline{\mathrm{x}})=\frac{(\delta)(\tau)}{\omega^{2}} \cdot \mathbf{Z}^{\frac{\delta}{\omega}-1}[1-\mathrm{z}] ; \quad 0<z<1
$$

which means that, $z \sim \beta\left(\frac{\delta}{\omega}, 2\right)$.

Assuming a squared-error loss function and informative prior, the bayes estimate of the parameter $\theta^{\omega}$ is given by

$$
\left(\theta^{\omega}\right)^{*}=\mathrm{E}(\mathrm{z} \mid \underline{\mathrm{x}})=\frac{\left(\frac{\delta}{\omega}\right)}{\left(\frac{\delta}{\omega}+2\right)} .
$$

Based on binary loss function, which is the mode of $\pi(z \mid \underline{x})$, the highest post estimate (HPE) of the parameter $\theta^{\omega}$ is given by

$$
\left(\theta^{\omega}\right)^{*}=\frac{\left(\frac{\delta}{\omega}-1\right)}{\left(\frac{\delta}{\omega}\right)} .
$$

Assuming a modified LINEX loss function, the bayes estimate of the parameter $\theta^{\omega}$ is given by

$$
\left(\theta^{\omega}\right)^{*}=\frac{\mathrm{E}\left(\frac{1}{\theta^{\omega}}\right)}{\mathrm{E}\left(\frac{1}{\left(\theta^{\omega}\right)^{2}}\right)}=\frac{(\delta-2 \omega)}{(\delta)}
$$

Also, under General entropy loss function, the bayes estimate of the parameter $\theta^{\omega}$ is given by

$$
\left(\theta^{\omega}\right)^{*}=\left[\mathrm{E}\left(\left(\theta^{\omega}\right)^{-\mathrm{q}}\right)\right]^{-\frac{1}{\mathrm{q}}}=\left[\frac{\delta(\tau)}{[\delta+\omega(1-\mathrm{q})]^{(\delta-\mathrm{q} \omega)}}\right]^{-\frac{1}{q}} .
$$

\subsubsection{Case II ( $\mathbf{c}$ and $\boldsymbol{\theta}$ are Un known)}

Assume that: $\mathrm{c}$ is distributed as a non-informative prior, $\theta$ is distributed as beta distribution where, $\mathrm{c}$ and $\theta$ are independent.

The joint prior density of $\mathrm{c}$ and $\theta$ can be written as follows:

$$
\pi(\mathrm{c}, \theta) \propto \frac{1}{\mathrm{c}} \theta^{\mathrm{a}-1} . ; 0<\theta<1, \mathrm{c}>0
$$

Combine the likelihood function (23) and the joint prior density (39) to obtain the joint posterior density of c and $\theta$ as follows

$$
\begin{aligned}
\pi(\mathrm{c}, \theta \mid \underline{\mathrm{x}}) & \propto \frac{1}{\mathrm{c}} \theta^{\mathrm{a}+\sum \mathrm{w}_{1}-1}-\frac{1}{\mathrm{c}} \theta^{\mathrm{a}+\sum \mathrm{w}_{2}-1} \\
& \propto \frac{1}{\mathrm{c}} \theta^{\mathrm{a}+\sum \mathrm{w}_{1}-1}\left[1-\theta^{\omega}\right]
\end{aligned}
$$

where, $\left.\mathrm{w}_{1}=\log 1+\left(\mathrm{x}_{\mathrm{i}}+1\right)^{-\mathrm{c}}\right\}, \mathrm{w}_{2}=\log (1+$

$$
\mathrm{xi}-\text { cand } \omega=(\mathrm{w} 2-\mathrm{w} 1)
$$

The jo int posterior density (40) can be rewritten as follows

$$
\pi(\mathrm{c}, \theta \underline{\underline{\mathrm{x}}})=\mathrm{K}_{\mathrm{c}}^{\frac{1}{1}} \theta^{\mathrm{a}+\sum \mathrm{w}_{1}-1}\left[1-\theta^{\omega}\right]
$$

where $\mathrm{K}$, is constant given by

$$
\mathrm{K}^{-1}=\int_{0}^{\infty} \frac{1}{\mathrm{c}} \mathrm{Q}^{-1}(\mathrm{c}) \mathrm{dc}
$$

and $\mathrm{Q}^{-1}(\mathrm{c})$ is given by (29) as follows

$$
\begin{gathered}
\mathrm{Q}^{-1}(\mathrm{c})=\int_{0}^{1} \theta^{\mathrm{a}+\sum \mathrm{w}_{1}-1} \mathrm{~d} \theta-\int_{0}^{1} \theta^{\mathrm{a}+\sum \mathrm{w}_{2}-1} \mathrm{~d} \theta=\frac{\omega}{(\delta)(\tau)} \\
\text { where } \delta=\left(\mathrm{a}+\sum \mathrm{w}_{1}\right), \tau=\left(\mathrm{a}+\sum \mathrm{w}_{2}\right), \omega=\left(\sum \mathrm{w}_{2}-\right. \\
\left.\left.\sum \mathrm{w}_{1}\right), \mathrm{w}_{1}=\log \operatorname{lif}_{1} 1+\left(\mathrm{x}_{\mathrm{i}}+1\right)^{-\mathrm{c}}\right\} \\
\text { and } \mathrm{w}_{2}=\log \left(1+\mathrm{x}_{\mathrm{i}}{ }^{-\mathrm{c}}\right) . \\
\mathrm{K}^{-1}=\int_{0}^{\infty} \frac{1}{\mathrm{c}} \frac{\omega}{(\delta)(\tau)} \mathrm{dc} .
\end{gathered}
$$

\section{Conclusions}

The purpose of this paper is to explore a new lifetime distribution suitable for modeling discrete data, that was achieved by applying the general approach of discretizing a continuous distribution on the continuous model of Burr type III in order to introduce the discrete version of it, which is called discrete Burr type III distribution dBurrIII(c, $\theta)$. In this paper, we carry out a theoretical study of the obtained distribution discussing its distributional properties and reliability characteristics along with a graphical description. Also, we obtained and proved some important results on dBurrIII(c, $\theta$ ). In addition, estimation of the parameters is discussed based on the maximum likelihood method and Bayesian approach.

\section{ACKNOWLEDGEMENTS}

The author wishes to gratefully acknowledge the referees of this paper who helped to improve the presentation.

\section{REFERENCES}

[1] Lai, C.D., Xie, M. (2006). Stochastic Ageing and Dependence for Reliability. Springer science and Business media Inc, United states of America.

[2] Lawless, J.F (2003). Statistical Models and Methods for Lifetime Data. John-Wiley \& Sons Inc, Canada.

[3] Khan, M.S.A., Khalique, A. and Abouammoh, A. M. (1989). On estimating the parameters in a discrete Weibull distribution. IEEE- Transactions on Reliability, Vol. 38, Issue 3, pp. 384-350.

[4] Kulasekera, K.B. (1994). Approximate MLE's of the parameters of a discrete Weibull distribution with type I censored data. Elsevier- Microelectron. Reliab, Vol. 34, Issue 7, pp. 1185-1188.

[5] Kemp, A.W. (1997). Characterizations of a discrete normal distribution. Elsevier- Journal of Statistical Planning and Infernce, Vol. 63, pp. 223-229.

[6] Szablowski, P.J. (2001). Discrete normal distribution and its relationship with Jacobi theta fundions. Elsevier- Statistics \& Probability Letters, Vol. 52, pp. 289-299.

[7] Roy, D.(2003). The discrete normal distribution. Communication in Statistics-Theory and Methods, Vol. 32, Issue 10, pp. 1871-1883.

[8] Roy, D.(2004). Discrete Rayleigh distribution. IEEE-Transactions on Reliability, Vol. 53, Issue 2, pp. 255-260.

[9] Murthy, D.M., Xie, M., Jiang, R.(2004). Weibull Models. John-Wiley \& Sons Inc, Canada.

[10] Inusah, S. and Kozubowski, T.J (2006). A discrete analogue of the Laplce distribution. Elsevier- Journal of Statistical Planning and Infernce, Vol. 136, pp. 1090-1102.

[11] Krishna, H., Pundir, P.S. (2009). Discrete Burr and discrete Pareto distributions, Elsevier- Statistical Methodology, Vol. 6, pp.177-188.

[12] Jazi, M.A., Lai, C.D., and Alamatsaz, M.H. (2010). A discrete 
inverse Weibull distribution and estimation of its parameters. Elsevier- Statistical Methodology, Volume 7, Issue 2, 121-132.

[13] Deniz, E. G., and Ojeda, E. C. (2011). The discrete Lindley distribution: properties and applications. Taylor and francis-Journal of Statistics Computation and Simulation, Volume 81, Issue 11, pp. 1405-1416.

[14] Nekoukhou, V., Alamatsaz, M.H., and Bidram, H. (2011). Discrete generalized exponential distribution of a second type. Statistics-iFirst, pp. 1-12.
[15] Nekoukhou, V., Alamatsaz, M.H., and Bidram, H. (2012). A discrete analog of the generalized exponential distribution. Communication in Statistics-Theory and Methods, Volume 41, Issue 11, pp. 2000-2013.

[16] AL-Dayian, G.R. (1999). Burr Type III Distribution: Properties and Estimation. The Egyptian Statistical Journal, ISSR, Cairo University, Vol. 43, pp 102-116. 